\title{
FÚTBOL CALLEJERO E PROCESSOS EDUCATIVOS: SABERES EMERGENTES DE EXPERIÊNCIAS CONVERGENTES
}

\section{FÚTBOL CALLEJERO AND EDUCATIONAL PROCESS: EMERGING KNOWLEDGE OF CONVERGENT EXPERIENCES}

\author{
Maurício Mendes-Belmonte ${ }^{1}$ \\ Nathan Raphael Varotto ${ }^{2}$ \\ Luiz Gonçalves Junior ${ }^{3}$
}

\begin{abstract}
Resumo: O objetivo deste estudo foi identificar e compreender os processos educativos emergentes da prática do Fútbol Callejero $(F C)$ em duas intervenções distintas, uma em contexto não-escolar, outra em escolar. A Intervenção-1 (i-1) ocorreu junto à parceria entre os projetos socioeducativos "Vivências em Atividades Diversificadas de Lazer" (VADL) e o "Mais que Futebol" (MQF) realizado com crianças e adolescentes de 6 a 14 anos, e a Intervenção-2 (i-2) foi desenvolvida junto a uma turma de Educação Física do $4^{\circ}$ do Ensino Fundamental da Rede Pública do Estado de São Paulo com estudantes de 9 a 10 anos. Destacamos que o $F C$ fora pensado e criado na Argentina e preconiza: desenvolvimento de partidas de futebol disputadas em três tempos; composição de equipes mistas (meninos e meninas); ausência de árbitros/as; atribuição de pontos aos pilares Respeito, Companheirismo e Solidariedade. Pautamo-nos na investigação qualitativa com inspiração na fenomenologia. Consideramos que o $F C$ é práxis educativa com potencialidades para nos ensinar a ser mais, a refletirmos criticamente acerca de nossa ação com outrem e com o mundo, desafiando-nos e nos convidando ao protagonismo, à construção coletiva e mobilização para uma convivência acolhedora, inclusiva e solidária, na qual a dialogicidade é a base das relações.
\end{abstract}

Palavras-chave: Processos Educativos; Fútbol Callejero; Pedagogia Dialógica; Motricidade Humana.

\begin{abstract}
The aim of this study was to identify and comprehend the emerging educational processes from the practice of Fútbol Callejero (FC) in two different interventions, within non-school context and without school context. Intervention-1 (i-1) occurred together with the partnership between the socioeducational projects "Experiences in Diversified Leisure Activities" (VADL) and "More than Football" (MQF), carried out with children and adolescents from 6 to 14 years of age, and Intervention-2 (i-2) was developed with a Physical Education class from the 4th grade of Elementary School of the State of São Paulo Public System with students from 9 to 10 years of age. We emphasize that FC was designed and created in Argentina and implies the development of football matches played in three periods; mixed team composition (boys and girls); absence of referees; point attribution based on the pillars Respect, Companionship and Solidarity. We are guided by qualitative research based on phenomenology. We believe that FC is an educational practice with the potential to teach us to be better, to reflect critically about our own action with others and with the world, challenging and inviting us to protagonism, collective construction and mobilization for a welcoming, inclusive and solidarity, in which dialogicity is the basis of relationships.
\end{abstract}

Keywords: Educational Process; Fútbol Callejero; Dialogic Pedagogy; Human Motricity.

\section{Introdução}

${ }^{1}$ Doutor em Educação, Universidade Federal de São Carlos (UFSCar). Ministério da Saúde (MS), Sorocaba, São Paulo, Brasil. E-mail: prof.mauricio015@gmail.com

${ }^{2}$ Mestre em Educação, Universidade Federal de São Carlos (UFSCar). Universidade Federal de São Carlos, São Carlos, São Paulo, Brasil. E-mail: varotton@gmail.com

3 Pós-Doutor pelo Instituto de Ciências Sociais da Universidade de Lisboa (ICS-UL). Universidade Federal de São Carlos (UFSCar), São Carlos, São Paulo. Brasil. E-mail: luiz@ ufscar.br 
No presente artigo nos dedicamos às análises dos dados referentes a duas intervenções desenvolvidas por nós, autores, que ao serem realizadas em contextos de espaço e de tempo distintos estabeleceram convergências ao elencarem o Fútbol Callejero como objeto de estudo, bem como ao possuírem a perspectiva qualitativa com inspiração fenomenológica (MARTINS; BICUDO, 1989; GARNICA, 1997) em suas trilhas metodológicas.

Esclarecemos para o leitor e/ou leitora que em uma possível tradução para o idioma português, poderíamos nos referir ao Fútbol Callejero a partir das expressões "Futebol de Rua" ou "Futebol Rueiro". Todavia, procurando melhor especificar nosso objeto de estudo, optamos por manter o uso em língua espanhola, ou seja: "Fútbol Callejero" $(F C)$, haja vista que no contexto brasileiro sua tradução poderia indicar um sem número de práticas de futebóis desenvolvidas nas ruas, mas que possuem intencionalidades distintas daquela que foi originalmente direcionada para o $F C$, qual seja: a educativa.

Em observação ao Fútbol Callejero, salientamos que se trata de uma prática de Educação Popular que nasceu em meados de 2001 no bairro de Moreno, periferia empobrecida da região metropolitana de Buenos Aires - Argentina (ROSSINI et al., 2012; BELMONTE; GONÇALVES JUNIOR; SOUZA JUNIOR, 2018). Neste contexto, em uma de suas andanças pelo território de Paso del Rey - região que representa um aglomerado de bairros situados nas imediações de Buenos Aires, dentre os quais o já citado Moreno - o educador popular e ex-jogador de futebol Fábian Ferraro percebeu que em partidas de futebol que eram autonomamente organizadas e disputadas por jovens que, inclusive, compunham gangues/facções antagônicas, tinham seus conflitos e diferenças suspensos/as durante o desenvolvimento dos jogos que ocorriam sem a presença de um árbitro (ROSSINI et al., 2012; COON; DURBIN, 2013).

Em diálogo com algumas lideranças dessas gangues/facções, o educador soube que os jovens estabeleciam acordos antes do início de cada partida que envolviam, por exemplo: não portar armas; a proibição do consumo de drogas durante as partidas; proibição de ofensas ou de situações de desrespeitos de uns-com-outros (para citar alguns desses acordos).

Atento à conjuntura socioeconômica de seu país, e sensibilizado pela situação de marginalização, violência e preconceito sofrida pelos/as jovens empobrecido/as, o 
educador popular e ex-jogador de futebol Fábian Ferraro percebeu tanto a potencialidade destes jovens no processo de autonomia para estabelecimento de acordos e convivência respeitosa durante as partidas, quanto o encanto e o poder que o futebol exercia sobre estas juventudes, capaz de reunir/congregar jovens em torno de sua prática (COON; DURBIN, 2013; BELMONTE; SOUSA JUNIOR, 2017).

Admirado com o poder de auto-organização daqueles jovens Fábian Ferraro convidou as lideranças juvenis dos bairros para ampliar a frequência destes jogos de futebol autogestionários (ocorriam sem a presença de um árbitro) e que tinham o conjunto de regras estabelecido ao início de cada partida. Nesta empreita, em um movimento de abertura e diálogo ${ }^{4}$ com aqueles jovens, o citado educador (re)aprendeu com eles possíveis alternativas para superação da violência, sendo o Fútbol Callejero um caminho possível. Pois, de acordo com Rossini et al., (2012):

\begin{abstract}
El fútbol callejero fue concebido como una respuesta a las tantas crisis que afectan y atraviesan el "ser joven" en América Latina. Fútbol, para atraer la atención y vincular a los participantes desde una experiencia que recogiera sus intereses y gustos. Callejero, porque proponía volver a las raíces del fútbol de "potrero", donde los participantes coinciden en llevar adelante un partido de fútbol de manera auto regulada y tácitamente estableciendo un marco de respeto ${ }^{5}$ (p. 12).
\end{abstract}

A dinâmica de desenvolvimento do Fútbol Callejero, também é chamada de Metodologia Callejera (CASTRO, 2018; BELMONTE, 2019), possui algumas singularidades que a caracterizam. A primeira que destacamos aponta para a organização de disputadas por Equipes Mistas, ou seja, formadas por meninos e meninas. Apelanz (2016) comenta que no início das atividades com o $F C$ foi percebida uma baixa participação das meninas e mesmo aparentemente integradas no jogo não tinham uma participação satisfatória, posto que os meninos evitavam passar a bola para elas, inviabilizando uma autêntica participação/inclusão delas. Para superação deste cenário foi necessária à efetiva experiência do desconforto, na qual as soluções não partiram de uma teoria, mas da experimentação mesma da situação de desigualdade, conforme sinaliza Apelanz (2016):

\footnotetext{
${ }^{4}$ Belmonte (2019), em sua tese de doutorado, identifica convergência na primazia do diálogo no Fútbol Callejero de Fábian Ferraro e na Pedagodia Dialógica de Paulo Freire.

5 "O fútbol callejero foi concebido como uma resposta para as muitas crises que afetam e atravessam o 'ser jovem' na América Latina. Futebol, para atrair a atenção e vincular o participante desde uma experiência que recorreu aos seus interesses e gostos. Callejero, porque propôs voltar as raízes do futebol de rua, onde os participantes concordam em levar adiante uma partida de futebol de maneira autorregulada, estabelecendo tacitamente um marco de respeito" (ROSSINI et al., 2012 p. 12 - tradução livre).
} 
La concepción de que por ser mujer, la mujer queda aislada del deporte no concuerda con la realidad de la práctica de muchas mujeres. Por lo tanto era necesario romper con esos estereotipos desde la experiencia. Desde esa realidad, que nace de lo que sucede y no de la teoría, aparece la necesidad de generar ciertas reglas para jugar al fútbol incorporando, aceptado $\mathrm{y}$ legitimando el papel de la mujer en fútbol callejero ${ }^{6}(\mathrm{~s} / \mathrm{p})$.

Outra particularidade é que seus jogos estão organizados em 3 tempos. Assim temos que no "10 Tempo" os/as participantes formam um círculo para estabelecerem coletivamente acordos sobre as regras. Estas são anotadas/registradas por um/a mediador/a. Já no "2o Tempo" ocorre o jogo propriamente balizado pelas regras previamente estabelecidas pelos/as participantes. Por fim, no " $3^{\circ}$ Tempo" ou "Mediação" são problematizadas as situações ocorridas no jogo e os/as participantes expõem seus pontos de vista junto ao/a mediador/a, que atua como um/a facilitador/a do diálogo entre as equipes (VAROTTO; SOUZA JÚNIOR, 2019). Durante o $3^{\circ}$ Tempo é que são contabilizados os pontos conquistados por cada equipe, uma vez que o gol não é o único que determina a equipe vencedora.

A Metodologia Callejera também estabelece que atitudes afeitas ao Respeito, ao Companheirismo e à Solidariedade se configuram como os pilares que alicerçam a prática do Fútbol Callejero (ROSSINI et al., 2012; BELMONTE; GONÇALVES JUNIOR, 2018; VAROTTO et al., 2018), de tal modo que cada um destes pilares também são mote de atribuição de pontos durante o $3^{\circ}$ Tempo: quando em círculo, ocorre novo espaço para diálogo entre os/as participantes, tendo em vista a avaliação de cada um dos pilares, cujos critérios foram sintetizados da seguinte maneira por Belmonte e Souza Junior (2017):

$\checkmark$ Respeito: Avaliar se os/as jogadores/as das duas equipes respeitaram as regras que foram combinadas durante o $1^{\circ}$ Tempo, bem como se foi estabelecida uma relação respeitosa entre os/as participantes da partida: tanto aqueles/as que compõem uma mesma equipe (intra-equipe), quanto a relação com os/as jogadores da equipe oponente (inter-equipe). No desenvolvimento da mediação alguns questionamentos podem auxiliar o/a mediador/a suscitar o debate: "Houve respeito neste jogo?"; “As regras foram respeitadas?"; “Alguém se sentiu desrespeitado/a?”; “As equipes merecem o ponto de respeito?".

\footnotetext{
6 “A concepção de que por ser mulher, a mulher ficaria ilhada do esporte não coincide com a realidade da prática de muitas mulheres. Para tanto, era necessário romper com os estereótipos desde a experiência. Desde esta realidade, que nasce o que lhe sucede, não de uma teoria, aparece a necessidade de criar certas regras para jogar o futebol incorporando, aceitando e legitimando o papel da mulher no Fútbol Callejero" (APELANZ, 2016, s/p, tradução livre).
} 
$\checkmark$ Companheirismo: Este pilar possui critérios exclusivamente intra-equipe, ou seja: procura avaliar se os/as participantes se mobilizaram para incluir seus/suas companheiros/as de equipe. O/A mediador/a deverá auxiliar o grupo para identificação, da manifestação, ou não, de atitudes que procuraram oportunizar uma participação equitativa e justa para todos/as integrantes de cada equipe. No momento de análise do Companheirismo algumas problematizações podem auxiliar, tais como: "Ambas as equipes merecem o ponto de companheirismo?"; “As equipes se mobilizaram para que todos/as do time participassem do jogo?"; “Toda gente está satisfeita com sua participação?”.

$\checkmark$ Solidariedade: Diferentemente do Pilar anteriormente apresentado, o critério para avaliação da Solidariedade é inter-equipe, ou seja: procura promover a reflexão acerca das atitudes que os/as integrantes de uma determinada equipe empreenderam em solidariedade/auxílio aos/às jogadores/as da equipe oposta, priorizando a intencionalidade de jogar-junto ou jogar-com-outrem, tencionando a competitividade exacerbada expressa pelo jogar-contra-outrem. Assim, algumas problematizações podem contribuir no momento da avaliação: "Houve solidariedade durante a partida?"; "Qual, ou quais foram os gestos de solidariedade durante o jogo?”; “As equipes merecem o ponto de solidariedade?".

Ainda apresentando os elementos que compõem a dinâmica metodológica do $F C$, apresentamos que em seu desenvolvimento ocorre a substituição da figura de um/a árbitro/a por um/a Mediador/a, cuja função é de facilitar o diálogo entre os/as jogadores/as nos diferentes momentos de uma partida, de maneira a não intervir diretamente nas intercorrências de um jogo, outrossim, deve incentivar que os/as jogadores/as decidam e encaminhem todas as demandas que emergem da partida (VAROTTO; LEMOS; FÁBIS, 2019).

As ações de um Mediador/a circunscrevem: tomar nota das regras que foram estabelecidas durante o $1^{\circ}$ Tempo de uma partida; observar, durante o $2^{\circ}$ Tempo (ou "tempo de bola rolando"), as atitudes que possuem relações com as regras estabelecidas para a partida, bem como aquelas afeitas à cada um dos pilares. Atentos a estes eventos, durante o $3^{\circ}$ Tempo o/a Mediador/a deverá problematizar com os/as participantes a conquista dos pontos relativos aos pilares, cuja atribuição ocorre por acordos e/ou consenso estabelecido pelos/as jogadores/as (ROSSINI et al., 2012; BELMONTE; GONÇALVES JUNIOR; SOUZA JÚNIOR, 2018). 
Para prosseguir com nosso estudo, após a apresentação de nosso objeto de estudo, compartilhamos com Oliveira et al., (2014) a compreensão de que as manifestações de processos educativos não se restringem ao ambiente escolar, identificando, assim, que a educação é inerente as diversas práticas sociais de que participamos e nas quais convivemos uns com os outros, ensinando e aprendendo ao longo da vida. Corroborando estão Gonçalves Junior, Carmo e Corrêa (2015) ao comunicarem que processos educativos:

[...] ocorrem em uma relação mútua de aprendizagem e não só em uma situação em que um ensina ao outro, tendo como pressuposto fundamental para seu desenvolvimento o diálogo equitativo e a intencionalidade dirigida para a cooperação, superação, o ser mais, demandando autonomia, possibilidade de decisão e de transformação. Tais condições permitem aos envolvidos compreender em contexto, valores e códigos do grupo, da comunidade e da sociedade em que vivem, tendo a possibilidade de refletir criticamente sobre sua própria condição de pertencimento ao mundo com os outros, educando e educando-se, tornando-se pessoa ${ }^{7}$ (p. 176-177).

Iniciaremos a seguir uma breve descrição do percurso metodológico empreendidos em nossas intervenções (i-1 e i-2). Em seguida traremos a descrição e análise das convergências que identificamos, de modo a colocar em diálogo os saberes que emergiram de cada um dos contextos investigados.

\section{Fútbol Callejero à luz da perspectiva qualitativa: caminhos convergentes}

Des-cobrir o oculto constituirá um movimento, um discurso através de um caminho (Weg em alemão, hodós em grego: méthodos; caminho que se percorre) $\mathrm{O}$ processo de descobrir o ser é um método. No pensamento moderno esse processo será invertido, será outro hodós, outra direção, outro sentido (DUSSEL, 1974, p. 24).

No desenvolvimento das intervenções que colocamos em diálogo no presente artigo nos apropriamos dos horizontes metodológicos da investigação qualitativa. Sob este prisma o ato de pesquisar adquire novos contornos, pois ganha relevo a dimensão de "circularidade", de dar voltas em torno do fenômeno pesquisado, "[...] em que se deseja compreender, não se preocupando única e/ou aprioristicamente com princípios, leis e generalizações, mas voltando o olhar para a qualidade" (GARNICA, 1997, p. 2).

Conforme apontado anteriormente, embora o desenvolvimento das intervenções tenha ocorrido em contextos distintos de espaço e de tempo, nosso movimento de aproximação e convergência realizado para produção deste artigo esteve intencionado

\footnotetext{
${ }^{7}$ Para aprofundamento sugerimos a leitura de: Oliveira et al., (2014); Brandão (2002); Freire (2015); Freire (2005); Silva (2003).
} 
em explicitar uma lógica de continuidade, circularidade para o aprofundamento da reflexão acerca das potencialidades educativas do $F C$, em lugar de realizar uma equivocada e reducionista comparação entre os dados das intervenções.

A inserção em ambos os contextos ocorreu de maneira a atuarmos como educadores-investigadores aos auspícios do método da pesquisa participativa que, de acordo com Streck e Adams (2012):

[...] estabelece-se uma relação de complementaridade entre os sujeitos envolvidos, cabendo sempre uma tarefa especial ao pesquisador, mormente na leitura crítica do contexto. Ao assumir uma atitude ativa na investigação no campo educativo, o pesquisador constata, intervém, educa e educa-se ( $\mathrm{p}$. 254).

Procuramos realizar o exercício de inserção cuidadosa e escuta atenta nos integrando e compondo a comunidade participante. Assim, após colher autorização dos/as colaboradores/as e seus/suas respectivos/as responsáveis iniciamos as intervenções em campo e as suas respectivas coletas de dados, feitas a partir da confecção de Diários de Campos, envolvendo os registros sistemáticos das observações de aspectos descritos e reflexivos, em conformidade com a proposta de Bogdan e Biklen (1994).

Os aspectos descritivos registrados pelos/as pesquisadores/as podem englobar: retratos dos sujeitos (incluindo sua aparência, roupas, falas, ações); reconstruções do diálogo (as conversas e os gestos, expressões faciais); descrição do espaço físico (através de desenhos ou mesmo descrições das mobílias, piso, paredes, pintura); relatos de acontecimentos particulares (caso ocorram e sejam pertinentes); descrição das atividades (incluindo as atitudes dos participantes); comportamento do/a observador/a (considerando-se a si próprio, suas atitudes, suas suposições e tudo que possa afetar a coleta dos dados). A porção reflexiva dos diários indica: reflexões sobre o método; reflexões sobre conflitos e dilemas éticos; reflexões sobre o ponto de vista dos observadores e pontos de clarificação.

Com vistas a contemplar as premissas éticas de pesquisas desenvolvidas com colaboração de seres humanos, salientamos que todos os nomes dos/as participantes, tanto da i-1, quanto da i-2, foram substituídos por nomes fictícios.

A partir dos saberes trazidos neste texto, e que comunicaram a origem e dinâmica metodológica do $F C$, reunimos esforços para colocar em diálogo os dados de duas intervenções desenvolvidas por nós, investigadores, com o objetivo identificar e 
compreender os processos educativos emergentes da prática do $F C$ em duas intervenções distintas, uma em contexto não-escolar, outra em escolar.

A saber, a "Intervenção-1" (i-1) ocorreu junto à parceria entre os projetos socioeducativos "Vivências em Atividades Diversificadas de Lazer" (VADL) - do Departamento de Educação Física e Motricidade Humana da Universidade Federal de São Carlos (DEFMH/UFSCar), e o "Mais que Futebol" (MQF) - da Associação Desportiva, Educacional e Social dos Metalúrgicos de São Carlos (ADESM). Doravante, tal parceria, caracterizada como uma situação não-escolar, será identificada apenas pelas siglas dos projetos que a compõe: "VADL-MQF". Participaram da "i-1" crianças e adolescentes (6 a 14 anos) e educadores/as participantes da parceria VADLMQF. O período de inserção em campo ocorreu de agosto a dezembro de 2016 na sede do Clube de Campo do Sindicato dos Metalúrgicos de São Carlos, cuja frequência dos encontros era semanal (terças-feiras) e totalizaram 9 diários de campo.

Já a "Intervenção-2" (i-2) foi desenvolvida em parceria com o professor responsável pelo ministro do componente curricular Educação Física, da Escola Estadual Bento da Silva Cesar, localizada no município de São Carlos. Neste contexto as vivências foram ministradas com estudantes (9 a 10 anos) que integraram uma das turmas do $4^{\circ}$ ano do Ensino Fundamental. A intervenção ocorreu no mês de setembro de 2017, cujos encontros ocorreram 2 vezes por semana (segundas e sextas-feiras) e somaram 6 diários de campo.

Após realizarmos nossas respectivas intervenções em campo e concluída a fase de coleta de dados, procedemos então para as suas análises. Trabalho que foi balizado inspirado na análise fenomenológica. Assim, conforme Martins e Bicudo (1989) realizamos diversas leituras dos Diários de Campo trazendo à luz trechos mais significativos registrados nos Diários de Campo em acordo com o objetivo da pesquisa. Tais trechos, denominados unidades de significados, foram sublinhados e identificados com numeração arábica crescente (ex: 1, 2, 3...), sendo a cada novo diário a contagem reiniciada.

Ao prosseguir com a análise percebemos articulação entre as diversas unidades de significados encontradas, caracterizando a formação de categorias temáticas, que nas palavras de Garnica (1997):

(...) é feita com base na análise das divergências e convergências expressas pelas unidades de significado, estando vinculada, ainda, a interpretações que o pesquisador faz para obter cada uma dessas convergências ou divergências. Disso, novos grupos são formados e, num processo contínuo de convergências e interpretações, sempre explicitadas, novas categorias abertas, 
mais gerais, vão-se formando. As generalidades resultantes dessa análise iluminam uma perspectiva do fenômeno, dado seu caráter perspectival p. 117).

Para o presente artigo, destacamos os processos educativos (sintetizados em categorias temáticas $)^{8}$ que emergiram dos dois contextos de pesquisas que foram desenvolvidas por nós, autores, apresentadas no tópico a seguir.

Iniciaremos, então, o exercício proposto por este artigo, qual seja: pôr em diálogo os dados registrados em diários de campo que compuseram a i.1 e da i.2, com o objetivo de identificar e compreender os processos educativos emergentes da prática do $F C$ das duas intervenções, uma em contexto não-escolar, outra em escolar.

\subsection{Futebol Callejero e Ubuntu: Eu sou porque nós somos!}

Ubuntu é a essência do ser humano. Ela fala de como a minha humanidade é alcançada e associada à de vocês de modo insolúvel. Essa palavra diz, não como disse Descartes, "Penso logo existo", mas "Existo porque pertenço". Preciso de outros seres humanos para ser humano (...). Posso ser eu só porque você é completamente você. Eu existo porque nós somos (...) (TUTU, 2012, p. 43).

A expressão ubuntu, que compõe a filosofia de muitos povos do continente africano, nos ensina sobre a importância de compartilhar nossa existência com-omundo-e-com-outrem. Tal sabedoria nos comunica que somos seres relacionais, dependemos mutuamente de outrem e dos demais seres vivos para existirmos. Corroborando, temos Tutu (2012) que reitera: "Em xhosa, dizemos: 'Umntu ngumtu ngantu'. É muito difícil passar essa expressão para outras línguas, mas poderíamos traduzi-la dizendo: "Uma pessoa é uma pessoa por intermédio de outras pessoas"” (p. 41).

Nos contextos da i.1 e da i.2 identificamos registros em diários de campo que indicavam que durante uma partida do $F C$ a preocupação em acolher e cuidar de outrem se fez presente. Destacamos adiante uma unidade de significado de um momento de elaboração de regras no contexto P1, na qual o pesquisador Maurício, que atuou como mediador de uma partida, dialogou com os/as participantes acerca de eleição de uma regra:

\footnotetext{
${ }^{8}$ A i.1 apresentou quatro categorias, a saber: A) Cuidado com outem, B) "É divertido", C) Ecologia das motricidades e D) Sinergia. Enquanto que a i.2 identificou três categorias, a saber: A) "Para valer o gol tem que passar por todos da equipe", B) "O mais importante não é o gol e sim os valores" e C) "Estaria melhor se eu tivesse jogado". Salientamos que as categorias temáticas cujos títulos aparecem entre aspas duplas procuram indicar que seus nomes são compostos por excertos de falas extraídas durante os diálogos de/com participantes.
} 
Maurício: Pessoal (...) qual regra que vocês gostariam de propor? Melissa: acho que não excluir os menores na hora de jogar. Maurício: E aí, como isso virou uma regra na hora de jogar (...) como que a gente vai fazer isso no jogo? Roberto: Tocando para eles. Melissa: Tocar para todos (i.1, VI-25) ${ }^{9}$.

No contexto da i-1 participaram juntos/as meninos e meninas com idade compreendida entre 6 e 13 anos. Assim foi notória a preocupação da participante Melissa e do Roberto, com 13 anos cada, em propor uma regra que contribuísse com a participação das crianças menores. Observando os pilares do Fútbol Callejero, compreendemos que a unidade de significado destacada aqui, vai ao encontro com os quesitos da Cooperação, uma vez que em nosso entendimento os/as participantes deveriam se mobilizar para "tocar para todos/as" de suas próprias equipes.

Reforçando percepção acerca de que a criação/transformação das regras que ocorre durante o $1^{\mathrm{o}}$ Tempo do Fútbol Callejero se mostra com grande potencialidade para manifestação do Ubuntu, possibilitando a participação de pessoas com diferentes níveis de habilidade tático-técnica para jogar futebol, a i.2 também trouxe apontamentos nesta mesma direção. Em diário de campo elaborado pelo pesquisador Nathan encontramos a proposição de regra que feita pelo participante Sans, em ocasião do quarto encontro em que a metodologia do Fútbol Callejero estava sendo desenvolvida: “" [Sans] Acho que pode ter uma regra de que para valer o gol a bola tem que passar por todos da equipe'. [Nathan] 'E perguntamos se todos/as concordavam com isso e todos sinalizaram positivamente"' (i-2, IV-6 - grifos nossos).

No exercício empreendido por nós, autores/pesquisadores, identificamos aproximações entre as atitudes dos/as participantes da i-1 e i-2 com os preceitos da filosofia africana do Ubuntu que expressaram o cuidado com outrem e/ou ações que conotam atitudes e gestos benfazejos, fazendo emergir a preocupação dos/as participantes em possibilitar uma convivência cuidadosa, conforme observamos na fala da participante Julha em justificativa ao pesquisador Maurício:

Maurício: Você quer sugerir regras? Julha: Não pode dar carrinho. Maurício: Hoje é importante, assim como nós fizemos na última terça que nós jogamos Fútbol Callejero, falar o porquê. Por que não pode dar carrinho? Julha: Porque machuca Maurício: Porque machuca? Vocês têm acordo com isso? (...) Todas as crianças participantes responderam que sim (i-1, III-7).

\footnotetext{
${ }^{9}$ Trata-se de uma sigla desenvolvida para proporcionar uma rápida visualização do contexto no qual foi retirado tal excerto. Deste modo, "i.1" se refere à "intervenção 1" (quando aparecer "i.2"estaremos nos referindo à "intervenção 2"); já os números em algarismos romanos indicam de qual diário de campo foi retirada a unidade de significado, que se encontra identificada com o conseguinte numeral em algarismo arábico. Assim, após a identificação da intervenção (1 ou 2) apresentamos "VI-25" no qual leia-se: "Diário de Campo seis, unidade de significado vinte e cinco".
} 
Conforme vimos no tópico anterior, o Fútbol Callejero busca proporcionar processos educativos ligados a adoção de uma postura dialógica para resolução de conflitos e à aquisição da autonomia para o protagonismo de seus/suas participantes para a luta e defesa de seus direitos e interesses (BELMONTE, SOUZA JÚNIOR, 2017; VAROTTO; GONÇALVES JUNIOR; LEMOS, 2017; ROSSINI et al., 2012). No entrelaçamento dos dados da i.1 e i.2 identificamos que durante o $3^{\text {o }}$ Tempo ou Mediação ocorreram diálogos nos quais as crianças e adolescentes realizaram o exercício, em consonância com a Ubuntu, de olhar para si e refletir sobre suas ações e/ou atitudes empreendidas com outrem de maneira respeitosa e justa. Com efeito, a prática desenvolvida e que agora é objetivo desta observação possibilitou a práxis do ser-para-si, se manifestando como um momento de interrupção para a escuta atenta a outrem, emergindo daí outro rosto, um/a outro/a outrem que também é outro "ser-parasi”. Nas palavras de Merleau-Ponty (2011):

É preciso que os Para $\mathrm{Si}$ - eu para mim mesmo e outrem para si mesmo se destaquem sobre um fundo de Para Outrem - eu para outrem e outrem para mim. É preciso que minha vida tenha um sentido que eu não constitua, que a rigor exista uma intersubjetividade, que cada um de nós seja simultaneamente um anônimo no sentido da individualidade absoluta e um anônimo no sentido da generalidade absoluta. Nosso ser no mundo é o portador concreto desse duplo anonimato (p. 601).

$\mathrm{Na}$ esteira desta compreensão acerca da emersão do ser-para-si, encontramos o diálogo empreendido em mediação ocorrida na i-2 e registrado em diário de campo pelo educador Nathan:

Eles/as refletiram, dialogaram e decidiram com base no que fora combinado no primeiro tempo: “(...) perguntamos se as equipes mereciam o ponto de Cooperação" e o participante Yuri disse: "A outra equipe merece porque percebi que as pessoas tentaram de toda maneira jogar igual, mas a minha equipe não porque só visou o gol" Então questionamos se concordavam com a fala de Yuri e todos/as concordaram. Assim, foram atribuídos três pontos de Cooperação para equipe dos/as participantes Anderson, Bianca, Roben, Jéssica, Neymar e Henrique (i.2, III-15).

Neste trecho, percebemos que o participante Yuri buscou, com honestidade, refletir acerca da postura que a própria equipe teve à luz dos quesitos da Cooperação, cuja análise entre as crianças participantes resultou no consenso acerca da não atribuição dos pontos do pilar Cooperação para a equipe do Yuri. Em outro momento do mesmo encontro registrado pelo pesquisador Nathan, houve diálogo semelhante na qual foi avaliada a Solidariedade:

Sobre a solidariedade Jéssica disse: "Eu acho que nenhuma equipe merece ponto porque uma hora o Cristiano Ronaldo caiu e ninguém parou para ajudar, em outro momento Roben parou para amarrar o tênis e ninguém esperou, por isso digo que nenhuma equipe pontua". Mais uma vez 
questionamos os/as envolvidos/as no jogo e concordaram com Jéssica, desta forma, não houve pontuação em solidariedade para as equipes (i-2, III-16).

Nos registros de nossos diários de campo também identificamos a criação de um espaço-tempo brincante, como dito por David: “David: Se bater na trave vale ponto. Klevis: Quanto? David: Um ponto. Maurício: Um ponto. Mas por que é que você quer sugerir essa regra? David: Porque é mais divertido" (i.1, III-8). Esta asserção põe em destaque que ao proporem regras para o jogo os participantes buscaram tornar sua prática mais divertida, ao seus gostos e interesses.

Em outro encontro desenvolvido no contexto da P1 alguns/algumas participantes sugeriram o desenvolvimento do Fútbol Callejero em uma quadra de areia que compunha o espaço onde ocorriam os encontros semanais. Nesta feita, os participantes Roberto e Vanessa destacaram a alegria de jogar na quadra de areia, ademais Roberto ainda ressaltou que para além de tornar o jogo mais divertido, a criação coletiva das regras possibilitou um jogo mais "equilibrado": "Roberto: Eu gostei mais do Fútbol Callejero hoje. (...) Estava mais equilibrado" (i-1, VI-32).

Reforçando nossa aproximação entre o Fútbol Callejero e Ubuntu e indicando processos educativos ligados ao reconhecimento de estabelecermos uma convivência pautada pelos valores de cooperação, solidariedade e respeito, finalizamos a apresentação desta categoria destacando o registro do pesquisador Nathan acerca da fala do participante Yuri, no contexto da i-2:

\begin{abstract}
A fim de compreender como foi participar deste processo, duas questões foram feitas neste último encontro aos/as estudantes para que pudéssemos dialogar, a saber: Como foi para vocês vivenciar o Fútbol Callejero? E, como podem utilizar os conhecimentos para ajudar as pessoas que tem dificuldades no jogo? (...) Para Yuri: "Foi legal porque dessa maneira foi possível perceber que o mais importante não é o gol e sim os valores" (i-2, VI-19).
\end{abstract}

\title{
2.2 Fútbol Callejero em ecologia de saberes
}

O ser humano está todo na motricidade, numa contínua abertura à realidade mais radical da vida. E não só a motricidade assume assim um caráter fundador, como dele e nela nasce uma ontologia nova, onde o que mais importa não são as performances de ordem físico-desportiva, mas o que se é, numa cumplicidade primordial com minha própria ontogênese, como ente que se faz e se renova quer individual, quer social e politicamente (SÉRGIO, 1999, p. 18).

Em análise aos contextos investigados durante a i-1 e a i-2, encontramos apontamentos comunicando que o $F C$ proporcionou uma ecologia de saberes advindo das experiências vividas por quem ali compartilhava o espaço de jogo, conforme observamos na ocasião de diálogo ocorrido no contexto da i-1 entre o pesquisador 
Maurício que, após exemplificar uma possibilidade de aplicação da dinâmica metodológica do $F C$ (desenvolvimento dos 3 tempos e avaliação da partida à luz dos pilares - Respeito Cooperação e Solidariedade) problematizou com os/as participantes a possibilidade da realização do jogo $\operatorname{My~God~}^{10}$ à luz da Metodologia Callejera:

(...) apresentei um possível exemplo, indicando que uma pessoa mais habilidosa poderia, em um gesto de solidariedade, não realizar o arremesso em uma pessoa menos habilidosa quando esta estivesse próximo à linha onde ficam posicionados/as os/as jogadores/as que irão fazer o arremesso (para queimar um/a adversário/a). Apresentei tal possibilidade salientando que se tratava de um exemplo de solidariedade. Diante destes meus esclarecimentos e exemplo, foi sugerido pelo participante David: David: Quando a bola estiver dentro do campo de quem está montando, poder pegá-la. Maurício: Poder pegar? Vocês topam turma? Robson: Não! (Respondeu de maneira bastante efusiva). Maurício: Porque Robson? Robson: Por causa que... Não pode entrar no campo que estão montando as latinhas. Maurício: Mas ele (o David) está dizendo agora que seria um gesto solidário que a equipe de quem está montando a lata permitir que o adversário entre (na cancha do adversário). Mas eu posso queimar o adversário? (Esta pergunta foi direcionada ao David, propositor da regra)... É só pra pegar a bola? Daí eu me afasto até a linha? David: Sim (no sentido de que só poderia queimar o adversário somente após ultrapassar a linha). Maurício: Olha... Achei legal hein? Leão: Eu topo! (Disse o participante de maneira espontânea e com excitação, chegando a levantar do assento da cadeira) (i-1, V-4).

O próximo excerto, também decorrente da i-1, retrata outra situação na qual a

lógica de avaliação dos pilares foi incorporada para a realização de um jogo chamado de "Garrafobol"11, em situação de reflexão durante a Roda Final, esta que é sistematicamente desenvolvida no projeto de extensão, sendo equivalente ao $3^{\circ}$ Tempo:

Maurício: Muito bem... É, "ceis" [entenda-se "vocês"] lembram que a gente tá vendo que nosso projeto pode ser como o Fútbol Callejero? Vocês acham que teve Cooperação hoje? Todos/as os/as participantes responderam, em coro, "sim". Continuei na investigação... Maurício: Em que momento? Quero-quero: No Garrafobol. David: No Garrafobol. Maurício: E como que foi a cooperação no Garrafobol. David: Ajudando a proteger a garrafa do

\footnotetext{
${ }^{10}$ Em sua dinâmica o jogo My God possui dois momentos. No primeiro: Uma equipe é responsável por montar uma base (composta por 6 latas vazias de achocolatado) no espaço central de jogo (em nossa prática utilizamos o círculo central da quadra, aproveitando a marcação do futebol). Neste espaço um/a participante por vez da equipe "invasora deve equilibrar todas as latas, de modo a formar um triângulo e, em seguida passar uma das pernas sobre esta base enquanto pronuncia em voz alta "My God". Feito isso este/a mesmo/a participante deve derrubar sua pirâmide conquistando 1 ponto para sua equipe, preparando o espaço para que outro/a colega de equipe repita a operação, e assim sucessivamente, somando pontos. O papel da equipe "defensora" é impedir a montagem das bases/pirâmides. Para tanto, os/as jogadores/as ficam posicionados distante do ponto central onde são montadas as pirâmides (em nossa prática utilizamos as linhas do "fundo" da quadra de vôlei) e com o auxílio de bolas (em média 4 bolas macias) tentam atingir corpo de seus/suas adversários/as, fazendo-os/as voltarem para fila de sua equipe, ou, atingindo a base/pirâmide (neste caso o/a "invasor/a" continua tentando montar a base). Após transcorrido um tempo pré-combinado (em nossa prática foram 8 minutos), as equipes têm seus papéis invertidos e os pontos contabilizados, auferindo vitória para equipe que conseguiu maior pontuação.

${ }^{11}$ Trata-se de uma variação do jogo "Queimada", cujo objetivo é atingir as garrafas descartáveis dos/as participantes da equipe oposta. Cada jogador/a recebe no início do jogo uma garrafa e deve protegê-la utilizando o próprio corpo. O/a participante que tiver sua garrafa derrubada (pela bola, ou acidentalmente pela própria pessoa que a defende, ou um/a colega de equipe) é considerado "morto", e passa a ocupar o "cemitério" (região para realização de arremessos situada nas margens do campo da equipe adversária).
} 
outro quando ele vai jogar a bola. Maurício: Ah... Uma salva de palmas pra ele... Porque a cooperação dentro do Fútbol Callejero é o que você faz para seu próprio parceiro. Pra que? Julha: Amigo... Pra ajudar uns aos outros. Maurício: Pra ajudar uns aos outros. Pra que ele se sinta incluído. Então, além de proteger a garrafa do outro, teve o passe da bola para um amigo? As crianças responderam, em coro, "sim" (i-1, VII-21).

Já no contexto da i-2, o professor de Educação Física ${ }^{12}$ que acompanhou a intervenção com $F C$ indicou o desenvolvimento da metodologia do $F C$ incorporada ao esporte Rúgbi, conforme o excerto extraído de diário de campo do pesquisador Nathan, na qual o professor diz: “(...) estou tentando aplicar o método do $F C$ no Rúgbi e está sendo muito bom" (i-2, VI-23).

A partir da exposição desta categoria, percebemos que a metodologia do Fútbol Callejero pode ser subsumida por outras práticas, com especial atenção para a práxis do diálogo e da reflexão acerca dos pilares, em todo o processo.

\section{Considerações: a guisa de outras práticas callejeras}

Daí a necessidade que se impõe de superar a situação opressora. Isto implica o reconhecimento crítico, a "razão" desta situação, para que, através de uma ação transformadora que incida sobre ela, se instaure uma outra, que possibilite aquela busca por ser mais (FREIRE, 2005, p. 34).

Ao modo da perspectiva qualitativa de pesquisa realizamos o movimento de "dar voltas" ao entorno do fenômeno investigado (GARNICA, 1997). Com efeito, neste artigo, revisitamos os dados dos diários de campos confeccionados a partir de duas intervenções empreendidas por nós, autores, que tiveram o objetivo de desvelar os processos educativos comunicados pelo entrelaçamento dos dados das duas intervenções.

A redução fenomenológica, feita a partir dos dados contidos nos diários de campo, o possibilitou a emersão de duas categorias temáticas. Em "Fútbol Callejero e Ubuntu: eu sou porque nós somos" revelamos que os/as participantes procuraram ao propor regras ( $1^{\circ}$ Tempo), ou nos momentos de Mediação ( $3^{\circ}$ Tempo), estabelecer uma relação de acolhimento e de cuidado com outrem, em uma atmosfera na qual "o mais importante não é o gol e sim os valores", conforme ilustrou a fala de Yuri, participante da i.2, nos dando indícios da potencialidade para superação da perspectiva da

\footnotetext{
${ }^{12} \mathrm{Na}$ ocasião da i.2 o professor da unidade escolar optou por manter seu nome real. Aqui, por uma questão de coerência ética, optamos por manter oculta sua identidade, conforme ocorreu com todos/as participantes das pesquisas.
} 
competição exacerbada e do individualismo em detrimento da construção de processos de conviver com outrem, conforme indica Boff (2006):

A convivência não apaga ou anula as diferenças. Ao contrário, é a capacidade de acolhê-las, deixá-las ser diferentes e, mesmo assim, viver com elas e não apesar delas. A convivência só surge a partir da relativização das diferenças em favor dos pontos em comum. Então surge a convergênia necessária, base concreta para uma convivência pacífica, embora sempre persistam níveis de tensão por causa das legítimas diferenças (grifos dos autores) (p. 33).

A categoria "Fútbol Callejero em ecologia de saberes" comunicou processo educativo relacionado à incorporação dos saberes originalmente concebidos para o método do Fútbol Callejero em outras práticas/jogos/esportes, tais como: proposição de regras feitas pelos/as próprios/as participantes; incorporação dos valores/pilares Respeito, Cooperação e Solidariedade; ausência de um/a árbitro/a durante uma disputa; realização de um diálogo ao final de modo a promover uma reflexão acerca dos eventos ocorrios durante uma partida. Compreendemos que tal processo suscita o aprendizado em movimento, dos modos de ser cooperativo/a, respeitoso/a e solidário/a, do protagonismo da/na transformação das práticas em acordo com o interesse de seus/suas participantes.

Consideramos, com isso, que o Fútbol Callejero não é mera atividade física, conforme dicotomia que por vezes se percebe entre físico e mental, é práxis educativa com potencialidades para nos ensinar a ser mais, a refletir criticamente acerca de nossa ação com outrem e com o mundo, nos desafiando e nos convidando ao protagonismo, a construção coletiva e mobilização para uma convivência acolhedora, inclusiva e solidária, na qual a dialogicidade é a base das relações estabelecidas entre toda gente participante. Neste processo vislumbramos potencialidade de colocar a dinâmica metodológica do Fútbol Callejero em ecologia com outras vivências, sendo incorporada a diferentes práticas, vivências, fazendo emergir novas práticas callejeras.

\section{Referências}

APELANZ, I. Movimiento fútbol callejero y las ligas COED en Estados Unidos. Revista Con Efecto, Buenos Aires, 25 de abr. 2016. Disponível em: $<$ https://revistaconefecto.wordpress.com/2016/04/25/movimiento-futbol-callejero-y-las-ligascoed-en-estados-unidos/>. Acesso em 09/08/2020.

BELMONTE, M. M. Fútbol Callejero: processos educativos decorrentes de uma motricidade emergente. 2019. Tese (Doutorado em Educação) - Programa de Pós-Graduação em Educação, Universidade Federal de São Carlos, São Carlos, 2019. 
BELMONTE, M. M.; GONÇALVES JUNIOR, L. Fútbol Callejero: nascido e criado no sul. Revista Crítica de Ciências Sociais, Coimbra, n. 116, v. 40, p. 155-178, set. 2018.

BELMONTE, M. M.; GONÇALVES JUNIOR, L.; SOUZA JUNIOR, O. M. Fútbol Callejero e educação das relações de gênero. In: SALDANHA, D. F.; GONZALEZ, R. H. (org.). Projetos sociais para crianças e adolescentes. Juiz de Fora: Garcia, 2018. p. 251-274.

BELMONTE, M. M.; SOUZA JÚNIOR, O. M. Fútbol Callejero: da sua historicidade à potencialidade para o ser mais. In: COLÓQUIO DE PESQUISA QUALITATIVA EM MOTRICIDADE HUMANA: ECOMOTRICIDADE E BEM VIVER, 7, 2017, Aracaju; São Cristóvão. Anais... São Carlos: SPQMH, 2017. p. 553-559.

BOFF, L. Virtudes para um outro mundo possível, Vol. II: convivência, respeito, tolerância. $1^{\text {a }}$ ed. Petrópolis: Vozes, 2006.

BOGDAN, R.; BIKLEN, S. K. Investigação qualitativa em educação: uma introdução à teoria e aos métodos. Porto: Porto Editora, 1994.

BRANDÃO, C. R. A educação como cultura. Campinas: Mercado de Letras, 2002.

CASTRO, L. E. A construção de valores orientada pela metodologia callejera na educação física escolar. 2018. Dissertação (Mestrado Profissional em Docência para Educação Básica) Programa de Pós-Graduação em Docência para a Educação, Universidade Estadual Paulista "Júlio de Mesquita Filho", Bauru, 2018.

COON, J.; DURBIN, Pa. Fútbol callejero y cambio en el conurbado de Buenos Aires.

Desarrollo de base revista de la fundacíon interamericana, Washington, v. 34, n. 1, p. 9-21, nov. 2013.

DUSSEL, E. D. Método para uma filosofia da libertação. São Paulo: Loyola, Edições, 1974.

FREIRE, P. Pedagogia do oprimido. 43. ed. Rio de Janeiro: Paz e Terra, 2005.

FREIRE, P. Pedagogia da esperança: um reencontro com a pedagogia do oprimido. 22. ed. Rio de Janeiro: Paz e Terra, 2015.

GARNICA, A. V. M. Algumas notas sobre pesquisa qualitativa e fenomenologia. Interface: comunicação, saúde, educação, Botucatu, v.1, n.1, p.109-122, ago. 1997.

GONÇALVES JUNIOR, L.; CARMO, C. S.; CORRÊA, D. A. Cicloviagem, lazer e educação ambiental: processos educativos vivenciados na Serra da Canastra. Licere, Belo Horizonte, v.18, n.4, p.173-208, dez. 2015.

MARTINS, J.; BICUDO, M. A. V. A pesquisa qualitativa em psicologia: fundamentos e recursos básicos. São Paulo: Moraes/EDUC, 1989.

MERLEAU-PONTY, M. Fenomenologia da percepção. 4. ed. São Paulo: Martins Fontes, 2011.

OLIVEIRA, M. W. et al. Processos educativos em práticas sociais: reflexões teóricas e metodológicas sobre pesquisa educacional em espações sociais. In: OLIVEIRA, M. W.; SOUSA, F. R. (org.) Processos educativos em práticas sociais: pesquisas em educação. São Carlos: EdUFSCar, 2014. p. 29-46. 
ROSSINI, L. et al. Fútbol callejero: juventud, liderazgo y participación - trayectorias juveniles en organizaciones sociales de América Latina. Buenos Aires: FUDE, 2012.

SÉRGIO, M. A racionalidade espistemica na educação física do século XX. In: SÉRGIO, M. O sentido e a acção. Lisboa: Piaget, 1999. p.11-30 (Coleção Epistemologia e Sociedade).

SILVA, P. B. G. Aprender a conduzir a própria vida: dimensões do educar-se entre afrodescendentes e africanos. In: BARBOSA, L. M. A.; SILVA, P. B. G.; SILVÉRIO, V. R. (org.). De preto a afrodescendente: trajetos de pesquisa sobre relações étnico-raciais no Brasil. São Carlos: EDUFSCar, 2003. p.181-197.

STRECK, D. R.; ADAMS, T. Pesquisa em educação: os movimentos sociais e a reconstrução epistemológica num contexto de colonialidade. Educação e Pesquisa, São Paulo, v. 38, n. 1, p. 243-257, mar. 2012.

TUTU, D. M. Ubuntu: sobre a natureza da comunidade humana. In: TUTU, D. M. Deus não é cristão. Rio de Janeiro: Thomas Nelson Brasil, 2012.

VAROTTO, N. R.; GONÇALVES JUNIOR, L.; LEMOS, F. R. M. "FútbolCallejero": processos educativos emergentes da prática social da mediação. Revista Kinesis, Santa Maria, v.35, n.3, p.91-100, set./dez. 2017.

VAROTTO, N. R. et al. "Fútbol Callejero" na Educação Física Escolar: processos educativos emergentes de uma intervenção. Rev. Bras. de Iniciação Científica (RBIC), Itapetininga, v. 5, n. 5, p. 104-120, out./dez. 2018.

VAROTTO, N. R.; SOUZA JÚNIOR, O. M. Fútbol Callejero: um olhar para os processos educativos. FuLiA/UFMG, Belo Horizonte, v. 4, n. 2, p. 43-60, maio/ago. 2019.

VAROTTO, N. R.; LEMOS, F. R. M.; FÁBIS, L. de C. Percepções de mediadores/as de Fútbol Callejero sobre a sistematização da formação para a mediação: do Fútbol Callejero ao Futebol de Rua. In: COLÓQUIO DE PESQUISA QUALITATIVA EM MOTRICIDADE HUMANA: MOTRICIDADE E INTERCULTURALIDADE, 8., 2019, Maputo, Moçambique. Anais... São Carlos: SPQMH, 2019. p. 59- 65.

Recebido em: 05 de junho de 2019.

Aceito em: 09 de abril de 2020. 